\title{
Editorial
}

\section{Place image as a normative construct; and some new ethical considerations for the field}

\author{
Place Branding and Public Diplomacy (2010) 6, 177-181. doi:10.1057/pb.2010.26
}

When journalists or politicians ask, as they often do, whether a certain presidential slip-up, a political or business scandal, a crime or trial, a civil disturbance or even a lost football match has damaged their country's reputation, it is always interesting to ask them, in turn, whether similar events in distant countries have affected their perceptions of those countries. The chances are they didn't even notice them. Why people should imagine that their country, their scandal is somehow more universal, more significant, more relevant to other people in other places, isn't much of a mystery: it's simply human nature to imagine that oneself, one's community and one's country are somehow central, and that others are somehow marginal. This isn't merely the fixation of superpowers or ex-empires, but appears to be a more or less universal human trait.

A Chilean journalist, for example, recently asked this author in an interview how much he felt the election of a rightwing government had affected Chile's image. The only possible response to such a question is that general public opinion outside Latin America probably doesn't know and doesn't care. There are over 200 countries in the world, and only a tiny minority of people take the trouble to follow the domestic politics of other countries. By way of reply, the author asked the journalist, "how has the election of a new centre-right government affected your perceptions of Hungary this year? And how was your view of Indonesia changed last year by the new six-party coalition of Susilo Bambang Yudhoyono?' Arguably it isn't good media relations to fire questions back at journalists, but the journalist in question was good-humoured, and immediately saw the point: despite being a member of a well-informed and internationally aware elite, she didn't recall either of these elections, both of which briefly created substantial interest in and around their neighbourhoods.

In June, the accusations by the French Sports Minister, Roselyne Bachelot, that her national team had 'tarnished the image of France' through their unsportsmanlike behaviour at the South African World Cup, were typical of the kind of language used by governments when praising or blaming their players' performances. The media regularly, and confidently, speaks of damage done to the images of countries: how heavy-handed policing during the G20 summit in London has damaged the image of Britain, how the outcome of the Swiss referendum on minarets has damaged the image of Switzerland, how the crimes of Josef Fritzl damaged the image of Austria, and so on, on an almost daily basis. This is undoubtedly powerful rhetoric, but is it really true?

It's hard to say for sure, but if reputations really were subject to damage 
by such commonplace phenomena, life would be unliveable. We'd spend most of our waking hours constantly revising our opinions about places, and people, and organisations and institutions, and we'd have no time for anything else. Reputations, those essential normative beliefs about the power, integrity and value of places, people and organisations, are part of the working structure of our lives, so it's hardly surprising if human consciousness instinctively builds a large amount of inertia into them. Imagine if we mistrusted every other human being, every organisation and every nation as we mistrust a stray dog. We'd be constantly on our guard, constantly questioning our preconceptions, and consequently never have the faith or trust or courage to get anything done.

The idea that national images are normative provides a useful perspective on the subject: this is, surely, why such images or 'brands' exist. They provide a handy method for people to evaluate the things that countries do. If those behaviours fail to fit the norm, either the norm has to be readjusted (something which we all tend to do rather unwillingly), or else it is rejected as being 'out of character'.

Brands and norms share the same basic characteristics: clarity, simplicity, memorability, distinctiveness and having the quality of being emblematic of a wide variety of different possible behaviours; they provide an interpretative key for external phenomena and the behaviour of other people. In order to understand external events and behaviours, we need a yardstick against which to measure them; and national images provide that yardstick when we are confronted with the behaviours of nations.

When attempting to evaluate the significance, for example, of America's invasion of Iraq, only a historian or some (but alas, not all) journalists and diplomats would carefully measure it against each of America's previous overseas engagements, and thus come to a view about it. In the minds of most people, however, some basic facts about America's more recent engagements, along with a host of recollections, opinions, beliefs, prejudices and other snippets relating to the country and its population, will have resolved themselves into a 'normal position' somewhere along the continuum from uncontrollable bully to inveterate peacekeeper. In each individual's imagination, that norm is where America sits, and the invasion of Iraq is measured against it.

If an individual sees the invasion of Iraq as closer to the 'uncontrollable bully' end of the scale than his or her normative position for the United States, then this might have the effect of recalibrating that personal norm slightly closer to the 'bullying' end of the scale. If it is perceived to be entirely coherent with the norm, it will simply reinforce that norm.

If it is perceived to be closer to the 'inveterate peacekeeper' end of the scale, it may well be rejected. This is because the instinct to preserve the norm is strong; and after all, even uncontrollable bullies don't behave like uncontrollable bullies 24 hours a day: just because they behaved somewhat more mildly on one particular occasion doesn't alter their fundamental character. However, if the milder behaviour is particularly striking or frequently repeated, it might eventually cause the image to be revised in a favourable direction. So the norm, in all cases, tends to have a strong bias against change, and in many cases against movement in one particular direction. Most of us are more likely, for example, to revise our estimations of the poverty of sub-Saharan African countries downwards rather than upwards, and more willing to upgrade our sense of the 'normal' state of violence and instability in Afghanistan than to downgrade it.

Does this imply that our normative beliefs about countries are in fact not entirely stable phenomena, but they represent a 'direction of travel' rather than a fixed position? Or are we simply more likely to take note of behaviours that intensify or corroborate our norms, creating a 'snowball' effect? In either case, it would seem worthwhile, when one is attempting to understand the way a country is perceived, to gain not merely a static picture of how it is perceived at a given moment in time, but also to gain a sense of the ways in which 
public opinion is more or less inclined to accept the possibility of that picture migrating.

The earlier reference to the United States in this case is not casual: over the years, the image of the United States in the Nation Brands Index has proved to be significantly more volatile than that of most other countries. This is probably because it is more the focus of attention than most other countries, more relevant in many ways to people than most, and consequently more liable to continual reassessment.

But the parallel with commercial brands, as ever, needs to be made with caution. Inanimate things (such as products) are of course inherently more stable and predictable than people or groups of people, so the normalising instinct exists in order to 'smooth out the peaks and troughs' in our perception of things that have behaviours, that is things made of people or animals: our minds are simply attempting to create an approximate behavioural median for animate phenomena so that we can treat them as if they were inanimate, and thus be spared the inconvenience of keeping our eye on them at all times.

Countries appear to be perceived as a hybrid of animate and inanimate, and this is a reasonable model: they are, after all, partly composed of predictable and inanimate things like landscape, and partly of unpredictable and animate things like governments, corporations and population. In any case, large numbers of people tend to change more slowly than individuals or small groups, so the instinct to treat countries as stable and predictable entities is particularly strong.

We live in turbulent times - indeed, we are living through what is not unreasonably described as a 'seismic' shift of economic and political power from West and North to East and South. In such times, our normative models are under particular pressure for constant revision, or at least constant vigilance in case they need revising. The individuals and bodies that fail to challenge their normative beliefs in such times, and whose opinions and behaviour continue to be guided by those norms are at particular risk of making the wrong decisions. The qualities of flexibility, imagination and a constant reassessment of conventional assumptions about the way the world works are indispensable in an age such as ours. These are the times in which investments in research and analysis of the outside world, of consumer attitudes and values and beliefs, of the behaviours of other states and other organisations, of the mood of voters and shareholders and the media, need to be increased rather than cut back. Many organisations will fail precisely because of such cuts.

A company, for example, which is guided today by the same perceptions of the role of China in global markets that it might reasonably have held 5 years ago is likely to find itself in trouble. Likewise, any government that regulates its overseas development policy according to the model of 5 years ago might find itself wasting an even larger proportion of its taxpayers' money than before.

This last example is a particularly topical one, as the whole model of foreign assistance and development is changing before our eyes. One could make a case that the entire edifice of state aid for developing countries, of the massive philanthropic (if partly self-interested) transfers of capital from rich countries to poor countries, will have disappeared or changed beyond recognition within the next 5-10 years. Many factors are driving this instability in the model: the growing inability of western donors to 'compete' for the attention of least developed countries against China's much larger, ever-growing and generally unconditional - or at least commercially based investments; the fiscal pressures faced by many donor governments as a result of the economic crisis; the dramatic expansion of specialised non-state actors into the aid 'business'; the rapidly changing and often complex economic makeup of many traditional recipients of aid (in the United Kingdom, for example, many argue that it no longer makes sense to be carrying out expensive poverty reduction campaigns in India, a country that funds its own space programme); and, not least, the dawning 
realisation that decades of aid have seldom achieved any measurable positive effects on the recipients, and in many cases have merely increased corruption and reduced the country's ability to feed itself.

For all these reasons, the conventional system of foreign aid is surely nearing some kind of 'crunch point', and the implications of this are widespread: not least, it must put into question the future strategy of the development arm of the United Nations, so much of which is organised around the model of state-to-state assistance and poverty relief. Assistance, especially in crises, will still be needed as much if not more than ever before, as inequality and poverty aren't going out of fashion, even if the methods of tackling them are: but the model for delivering it, and delivering it effectively and without collateral harm to the economies and images of the recipients, is in urgent need of reform

China's role in this question is axiomatic. Never before has a state committed such resources and so much ambition to driving not merely its image but also its interests, systems and values around the world. America did something analogous in the twentieth century, but its efforts were significantly held back and significantly diluted by having to deal with a democratic system back home. China has no such constraints, and can brand itself like a corporation - like Singapore or Dubai, but with 10000 times the resources and significantly more managerial freedom. Can China be encouraged to devote at least some part of its 'soft power' efforts to shared causes? Two things are certain: if it can't, its efforts at promoting its own values will be less effective in the long term; and if it can't, the rest of us are in deep trouble.

As this Editorial goes to press, the news of the release on Wikileaks of documents relating to the US campaign in Afghanistan provides yet another example of how the climate is changing around us in 'real time', and very probably for the long term. Governments and corporations have always found secrecy to be an important competitive instrument; to compete effectively (especially for a state in time of war) without secrets is always harder, slower and in some cases impossible. Yet this new product of the internet age is inescapable in its logic and its consequences: many organisations will respond by imposing ever more draconian strictures on their employees, and a few will try a little harder to work without secrets.

In a larger sense, the Wikileaks phenomenon is certainly another nail in the coffin of state propaganda. This author has often argued that state propaganda has become impossible in our infinitely connected world, because no government can wield control over all the sources of information reaching the consumer. More even than before, we are living in an age in which, on balance, truth gradually becomes an easier and cheaper policy than falsehood.

The implications of this fact for place 'branding' are inescapable: the vast majority of communications-based place 'branding' exercises, currently carried out by cities, states and regions, are nothing more than naked, ineffectual and indefensible exercises of state propaganda, and thus are even less likely to modify public opinion than before. Countries that do one thing and say another will not escape international scrutiny for long, and, by a satisfying twist of natural justice, the countries that will suffer most from any hypocrisy or double-dealing are certainly the ones that advertise most. As I once observed, commercial brands are as much an invitation to complain as they are a guarantee of quality: the more a country spends on promoting its virtues, the more it invites public scrutiny of its vices, and the greater the damage to its reputation when they are discovered.

From a broader perspective, the whole logic of place 'branding' as a tool of national competitiveness appears less and less in tune with the challenges of our age. The need to reconcile the fundamentally selfish motivations of 'nation branding' with the fundamentally collective nature of the principal challenges facing us today is a pressing one for the academic and practitioner community that Place Branding and Public Diplomacy hopes to represent. 
The study and practice of place image and national standing needs to move from its traditional narrow context of 'projecting soft power', enhancing competitiveness and other variants of national self-interest, to tackling the shared challenges that define our age. New, more legitimate, more democratic and more public-spirited forms of 'image management' are now necessary, some of which have already been sketched out in this author's earlier writings: bilateral public diplomacy, governmental social responsibility and the 're-branding' of multilateral institutions as part of their necessary reform in a networked age; but others haven't even been dreamed of yet.

For centuries, unbridled competition has been the standard model for nations competing in the world, just as it has been for corporations competing in individual marketplaces, but surely the demise (or at least the questioning) of the Washington Consensus must cause us to ask whether a new model of co-competition between states should now be given a chance.

This development is partly driven, as this author has outlined in his writing about Governmental Social Responsibility, by the converging and apparently rising moral and ethical standards of consumers: these are no longer domestic consumers of products and services, but global consumers of places, and their word is law; they are the true superpower of our age. But it is also driven by the fact that all national governments can do on their own is selfishly compete in an approximately zero-sum game.

Place 'branding' has been one of the more interesting tools of that scenario. Can it make itself useful and thus relevant in a new order, where collaboration is necessary for our survival as a species? What has it to offer? Does it deserve to survive?

These are among the newer questions that our community needs to address. No doubt the vast majority will continue to focus on ways of making money out of the natural weakness of governments for any kind of snake-oil that promises to fix their national image, especially if it is perceived to come from the revered 'private sector'. But it only takes a few to change the moral and philosophical climate of a discipline, and it is to those few that this appeal is directed.

Simon Anholt Managing Editor 